\title{
Patients' attitudes towards the role of dentists in tobacco cessation counselling after a brief and simple intervention
}

A. Ebn Ahmady, ${ }^{1}$ A. Homayoun, ${ }^{2}$ H.A. Lando, ${ }^{3}$ F. Haghpanah ${ }^{4}$ and M.H. Khoshnevisan ${ }^{1}$

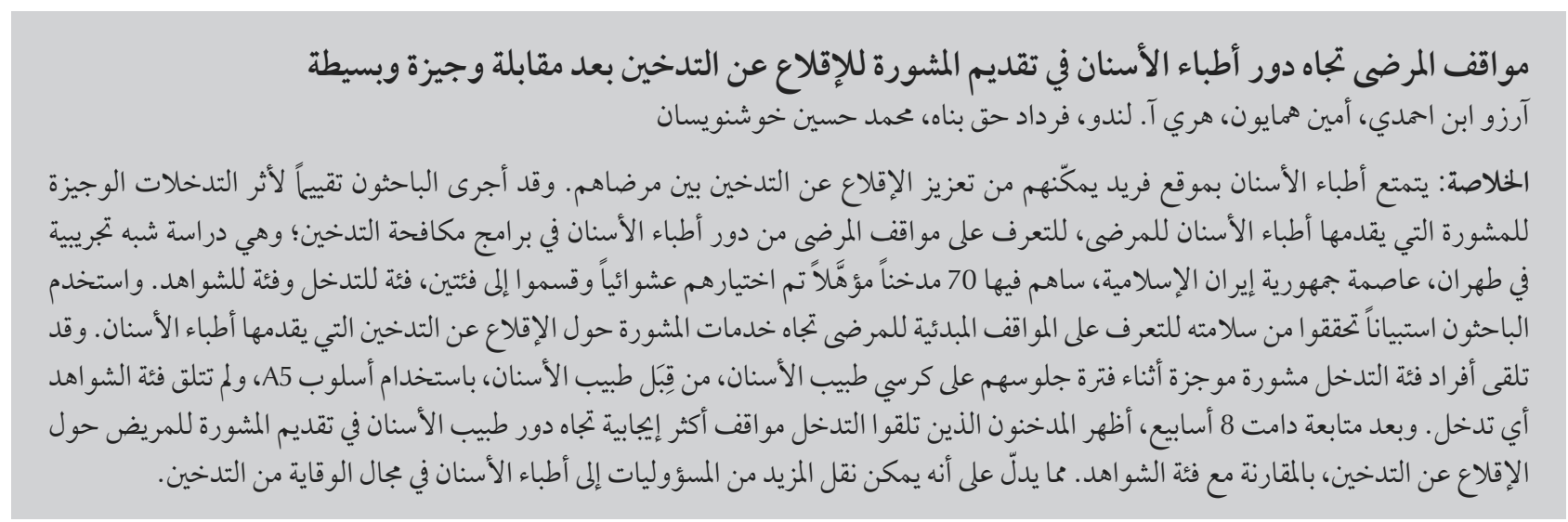

ABSTRACT Dental professionals are in a unique position to promote smoking cessation among their patients. We evaluated the effects of a brief counselling intervention by a dentist on patients' attitude towards the role of dentists in tobacco cessation programmes. In a semi-experimental study in Tehran, Islamic Republic of Iran, 70 eligible smokers were selected and randomly assigned to intervention and control groups. The initial attitudes of the patients regarding tobacco cessation counselling services provided by the dentist were determined using a validated questionnaire. The intervention group received a brief chair-side counselling by a dentist based on the 5 A's approach, while no intervention was provided for the control group. At 8-weeks follow-up, smokers receiving the intervention showed significantly more positive attitudes towards the role of the dentist in advising patients to quit smoking compared with those in the control group. More responsibility could be transferred to dentists for tobacco prevention.

Attitudes des patients vis-à-vis du rôle des dentistes en matière de conseils dans le sevrage tabagique après une intervention simple et brève

RÉSUMÉ Les professionnels en soins dentaires occupent une position idéale pour promouvoir le sevrage tabagique chez leurs patients. Nous avons évalué les effets d'une brève intervention de conseil par un dentiste sur l'attitude des patients vis-à-vis du rôle des dentistes dans les programmes de sevrage tabagique. Dans une étude semi-expérimentale menée à Téhéran (République islamique d'Iran), 70 fumeurs éligibles ont été sélectionnés puis répartis aléatoirement dans un groupe bénéficiant de l'intervention ou dans un groupe témoin. Les attitudes initiales des patients à l'égard des services de conseil sur le sevrage tabagique fournis par le dentiste ont été déterminées à l'aide d'un questionnaire validé. Les fumeurs du groupe bénéficiant de l'intervention ont reçu de brefs conseils reposant sur la méthode des $5 \mathrm{~A}$ pendant qu'ils étaient allongés sur le fauteuil et que le dentiste se tenait à côté, tandis que le groupe témoin n'a bénéficié d'aucune intervention. À la huitième semaine de suivi, les fumeurs ayant bénéficié de l'intervention avaient des attitudes nettement plus positives vis-à-vis du rôle de conseil du dentiste en matière de sevrage tabagique par rapport à ceux du groupe témoin. Des responsabilités supplémentaires pourraient être transférées aux dentistes en matière de prévention tabagique.

'Department of Community Oral Health, School of Dentistry, Shahid Beheshti University of Medical Sciences, Tehran, Islamic Republic of Iran (Correspondence to A. Ebn Ahmady: aebnahmady@yahoo.com). ${ }^{2}$ School of Dentistry, Babol University of Medical Sciences, Tehran, Islamic Republic of Iran. ${ }^{3}$ Division of Epidemiology and Community Health, School of Public Health, University of Minnesota, Minneapolis, United States of America. ${ }^{4}$ Sharif University of Technology, Tehran, Islamic Republic of Iran.

Received: 15/01/12; accepted: 19/03/12 


\section{Introduction}

Tobacco use is not only a major risk factor for general health, it also contributes substantially to oral health problems including oral cancer and periodontal disease. It is therefore an area where dental professionals should be actively engaged. Dental professionals are in a unique position to promote smoking cessation among their patients [1]. A systematic review reported that interventions conducted by oral health professionals increased tobacco abstinence rates at 12 months or longer, and suggested that further study of tobacco counselling within the dental office setting is important to identify effective intervention components for this profession [2].

The FDI World Dental Federation, in collaboration with the World Health Organization, has advised oral health professionals to become involved in smoking cessation programmes [3]. In its 2000 clinical practice guidelines and the 2008 update the United States Department of Health and Human Services (DHHS) suggested that dental care providers use the opportunity to ask and advise patients about their tobacco use and to arrange for brief intervention to be conducted in the dental office $[4,5]$. These guidelines recommend that all health care incorporate the Tobacco Cessation Counselling Programme (TCCP) as part of routine clinical care. The 5 A's approach is recommended for tobacco users willing to quit (asking about smoking status and providing advice and support to quit) and the 5 R's approach for tobacco users not willing to quit (motivational counselling intervention that emphasizes the risks of smoking and relevance of quitting). Some oral health professionals, however, feel that patients would not be receptive to tobacco control services, and that any attempts to provide such services may alienate their patients [6].
Although the prevalence of daily smoking in the Islamic Republic of Iran $(24.3 \%$ in males and $2.9 \%$ in females) is not as high as in some other nations, population growth means that the smoking burden is likely to rise in the future [7]. The country has more than 13000 dentists [8] and, based on recent unpublished data from the Iranian Medical Council, the number is estimated at around 22000 in 2010 [9]. In this study, we carried out a preliminary study to investigate the effect of brief counselling by a dentist on patients' attitude towards the dentist's role in tobacco cessation counselling. The findings should aid oral health professionals in conducting effective evidence-based counselling methods for tobacco cessation programmes in dental settings.

\section{Methods}

\section{Study design and setting}

The study design was a quasi-experimental, pre-post-test with 2 groups of dental patients assigned to an experimental (counselling intervention) or control (no counselling) group. The study was carried out in December 2010 at the Department of Oral Diagnosis at the School of Dentistry, Shahid Beheshti University of Medical Sciences in Tehran.

\section{Sample selection}

The sample size was 70 patients: 35 in the experimental group and 35 in the control group. Eligible patients were aged 19-70 years old, self-reported smokers, self-identified as Iranian nationality and living in Tehran. Patients were recruited by research assistants who verified their eligibility for participation and randomly assigned them to the experimental or control groups. Patients signed an informed consent form before participating in the study and receiving the counselling intervention.

\section{Study tools}

\section{Pre-post-test questionnaire}

In addition to basic demographic data, a questionnaire was designed to collect data about patients' smoking habits and cessation attempts: frequency of cigarette use; time of smoking after waking up; last time they attempted to quit; and highest number of quitting days during the past year. Participants were also asked whether they believed that tobacco use had any specific adverse effects on health.

The pre- and post-test evaluated the effect of the counselling on patients' attitudes to dentists' involvement in counselling There were 5 questions to determine patients' general attitudes to tobacco cessation counselling in the dental setting: "Dentists should concentrate only on dental problems not tobacco counselling"; "Dentists should refer smokers to quit centres"; "Dentists are responsible for tobacco counselling"; "I feel uncomfortable during dentist's tobacco counselling"; and "I prefer nicotine replacement therapy to tobacco counselling". A further 5 questions were based on the on the $5 \mathrm{~A}$ 's: "Do you think the dentist should ask about smoking status of the patients who smoke?"; "Do you think the dentist should advise patients to quit smoking?"; "Do you think the dentist should assess patients' willingness to quit smoking?"; "Do you think the dentist should assist patients who smoke to quit smoking?"; and "Do you think the dentist should arrange cessation service and follow up for patients who smoke?" Responses were scored on 5-point Likert scale from strongly disagree (score 0) to strongly agree (score 4).

\section{Intervention}

The intervention was a brief tobacco cessation counselling delivered by a trained dentist at the Department of Community Oral Health in locations convenient for the participants. To prevent inter-rater bias and avoid inconsistencies between trained counsellors 
(e.g. how much counsellors agree with guidelines) all counselling interventions were delivered by the same dentist.

The 5 A's approach includes: Asking patients about tobacco use; Advising users to quit; Assessing their readiness to quit; Assisting them with the quitting process; and Arranging follow-up to check on their progress. The 5 R's approach involves a motivational counselling intervention that emphasizes to the patient: the personal Relevance of quitting; the Risks of continued tobacco use; the Rewards associated with quitting; the Roadblocks to quitting; and the need for clinicians' on-going Repetition of the ' 5 R's' to promote patient decisions to make quit attempts $[4,5]$.

\section{Training of counsellors and quality control}

One dentist was selected and went through a lengthy training process conducted by an experienced tobacco control expert and an experienced tobacco cessation counsellor. The training involved the oral health effects of smoking, the benefits of quitting, evidence that dentists' advice can be effective in helping patients to quit smoking and the tobacco cessation counselling methods of the DHHS clinical practice guidelines [5].

After the training, the 2 trainers determined that the dentist was ready to do the intervention and the first counselling programme was observed by the trainers. The reports of the trainers were reviewed again by the project coordinator, who then determined when the dentist was ready to work alone. In an effort to attain a high degree of reliable judgement the trainers conducted supplementary intervention training in order to address the obstacles encountered by the dentist during the counselling programme and improve behavioural counselling for smoking cessation. The dentist also received necessary information explaining the $5 \mathrm{~A}$ 's and 5 R's techniques and the benefits of quitting smoking.

\section{Data collection}

The questionnaire was administered to obtain an initial assessment of the attitudes of the patients regarding tobacco cessation counselling by the dentist. Then the intervention group received the chair-side tobacco cessation counselling by the trained the dentist (based on the 5A's and 5 R's approach) $[4,5]$. No intervention was provided to the control group. The interventions were audiotaped and monitored randomly by the principal investigator. The post-test was carried out 8 weeks later. All patients completed both pre- and post-tests. To ensure compliance with the second test, participants received a consent letter that emphasized the importance of their participation in the post-test and were given 3 telephone reminders about the date of the post-test.

\section{Data analysis}

The data were described by frequency distributions, mean and standard deviation (SD). Independent sample t-test was used to compare the mean scores of patients' attitude towards role of dentist in tobacco cessation programme in control and experimental groups before and after intervention. Mann-Whitney U-test for the comparison of the patient's scores on the 5-point Likert attitude scales in the intervention and control group groups before and after receiving the counselling. Bonferroni corrections were applied for primary analyses. Significance was determined at $P<0.05$.

\section{Results}

\section{Patients' background data}

The mean age of the participants was 38.9 (SD 14.5) years, range 20-70 years. There was no significant difference in mean age between the control group [37.6 (SD 14.9) years] and intervention group [40.2 (SD 14.2) years]. The majority of patients were men ( $88.6 \%$ of control group and $91.4 \%$ of intervention group) and more than half were married (57.1\% of control group and $51.4 \%$ of intervention group). The most common reasons these patients gave for their dental visits were checkups (35.8\%), hygiene (20.6\%) and restorative services $(53.8 \%)$ (the total was greater than $100 \%$, as many patients were visiting the dental clinic for multiple reasons). The majority of the patients in both groups (79.5\%) had some type of dental insurance.

The mean number of cigarettes smoked per day in the intervention group [12.3 (SD) 8.1] was not statistically different from the control group it [14.7 (SD 9.7)]. The mean ages of initiation of smoking were 20.9 (SD 3.6) years and 20.0 (SD 2.7) years in the experimental and control groups respectively. At the start of the study $87 \%$ of the control group and $79 \%$ of the experimental group believed that tobacco use had adverse effects on their health, although these were not significantly different. Table 1 shows the distribution of responses in the 2 groups according to the frequency of cigarette use, time of smoking after waking up, most recent time of quitting and the highest number of quitting attempts during the past year. The experimental group waited longer for their first cigarette of the day and had attempted to quit more recently than the control group, but these differences were not statistically significant based on Fisher exact test.

\section{Patients' views on the provision of tobacco cessation counselling by dentists}

Figure 1 shows the opinions of the experiment and control groups of smokers, before and after the intervention, to the provision of tobacco cessation counselling by the dentist. Before counselling, there were no significant differences between the 2 groups in patients' views of dentists' counselling. Experience of counselling, 


\begin{tabular}{|c|c|c|c|c|}
\hline \multirow[t]{2}{*}{ Variable } & \multicolumn{2}{|c|}{$\begin{array}{l}\text { Control group } \\
\qquad(n=35)\end{array}$} & \multicolumn{2}{|c|}{$\begin{array}{l}\text { Experimental group } \\
\qquad(n=35)\end{array}$} \\
\hline & No. & $\%$ & No. & $\%$ \\
\hline \multicolumn{5}{|c|}{ Frequency of cigarette use } \\
\hline Every day & 30 & 85.7 & 28 & 80.0 \\
\hline Some days & 5 & 14.3 & 7 & 20.0 \\
\hline \multicolumn{5}{|c|}{ Time of smoking after waking up } \\
\hline $5 \mathrm{~min}$ & 3 & 8.6 & 0 & 0.0 \\
\hline $5 \mathrm{~min}$ to $30 \mathrm{~min}$ & 3 & 8.6 & 4 & 11.4 \\
\hline $30 \mathrm{~min}$ to $1 \mathrm{~h}$ & 10 & 28.6 & 5 & 14.3 \\
\hline After $1 \mathrm{~h}$ & 17 & 48.6 & 26 & 74.3 \\
\hline No response & 2 & 5.7 & 0 & 0.0 \\
\hline \multicolumn{5}{|c|}{ Time since last attempt to quit } \\
\hline 30 days & 2 & 5.7 & 9 & 25.7 \\
\hline $1-6$ months & 6 & 17.1 & 8 & 22.9 \\
\hline 7-12 months & 6 & 17.1 & 2 & 5.7 \\
\hline$>1$ year & 7 & 20.0 & 10 & 28.6 \\
\hline Don't remember & 14 & 40.0 & 5 & 14.3 \\
\hline No response & 0 & 0.0 & 1 & 2.9 \\
\hline \multicolumn{5}{|c|}{ Highest number of quitting days in past year } \\
\hline$<1$ week & 11 & 31.4 & 11 & 31.4 \\
\hline 1 week to 1 month & 4 & 11.4 & 7 & 20.0 \\
\hline $2-3$ months & 4 & 11.4 & 2 & 5.7 \\
\hline 4-6 months & 1 & 2.9 & 3 & 8.6 \\
\hline 7 months to 1 year & 1 & 2.9 & 0 & 0.0 \\
\hline$>1$ year & 4 & 11.4 & 1 & 2.9 \\
\hline Don't remember & 1 & 2.9 & 2 & 5.7 \\
\hline No response & 9 & 25.7 & 9 & 25.7 \\
\hline
\end{tabular}

however, had a significant effect on patients' views about the dentist's responsibility for counselling in the dental setting (Mann-Whitney test, $P=0.017)$. Post-counselling, significantly fewer smokers expressed feelings of discomfort during the dentist's tobacco counselling $(P=0.003)$ and significantly more patients accepted tobacco cessation counselling as a method, i.e. they were less likely to prefer nicotine replacement therapy to counselling $(P=0.020)$. After the intervention, experimental patients were significantly more willing to have dentists' support for quitting smoking, i.e. were less willing to be referred to a quit centre $(P=0.004)$. On the other hand, after counselling, patients did not significantly change their attitude towards whether the dentist should concentrate on dental problems not on tobacco counselling $(P=0.316)$.

Figure 2 compares the 2 groups responses, pre- and post-test, to questions about the 5A's of the TCCP. Preintervention there were no significant differences between the experimental and control groups, with both groups of smokers having fairly positive attitudes towards receiving tobacco smoking advice from the dentist, After the intervention significantly more of the experimental group had positive attitudes to dentists asking about smoking (Mann-Whitney test, $P<$ 0.001 ), advising patients to quit smoking $(P=0.049)$ and assessing patients' readiness to quit smoking $(P=0.036)$ than did the control group. No significant changes after the invention were seen comparing the 2 groups for the items on assisting patients who smoke to quit smoking $(P=0.187)$ and arranging cessation services and follow up for patients who smoke ( $P$ $=0.089$ ).

The attitude scores of control individuals did not change significantly pre- and post-test $(P=0.403)$, as illustrated by mean total scores of 67.6 (SD 11.0) and 69.1 (SD 16.8) respectively (Table 2). However, the mean attitude scores of the intervention group were significantly higher after the tobacco counselling $[68.0($ SD 13.5) versus 77.4 $(\mathrm{SD} 15.4)](P=0.009)$. 


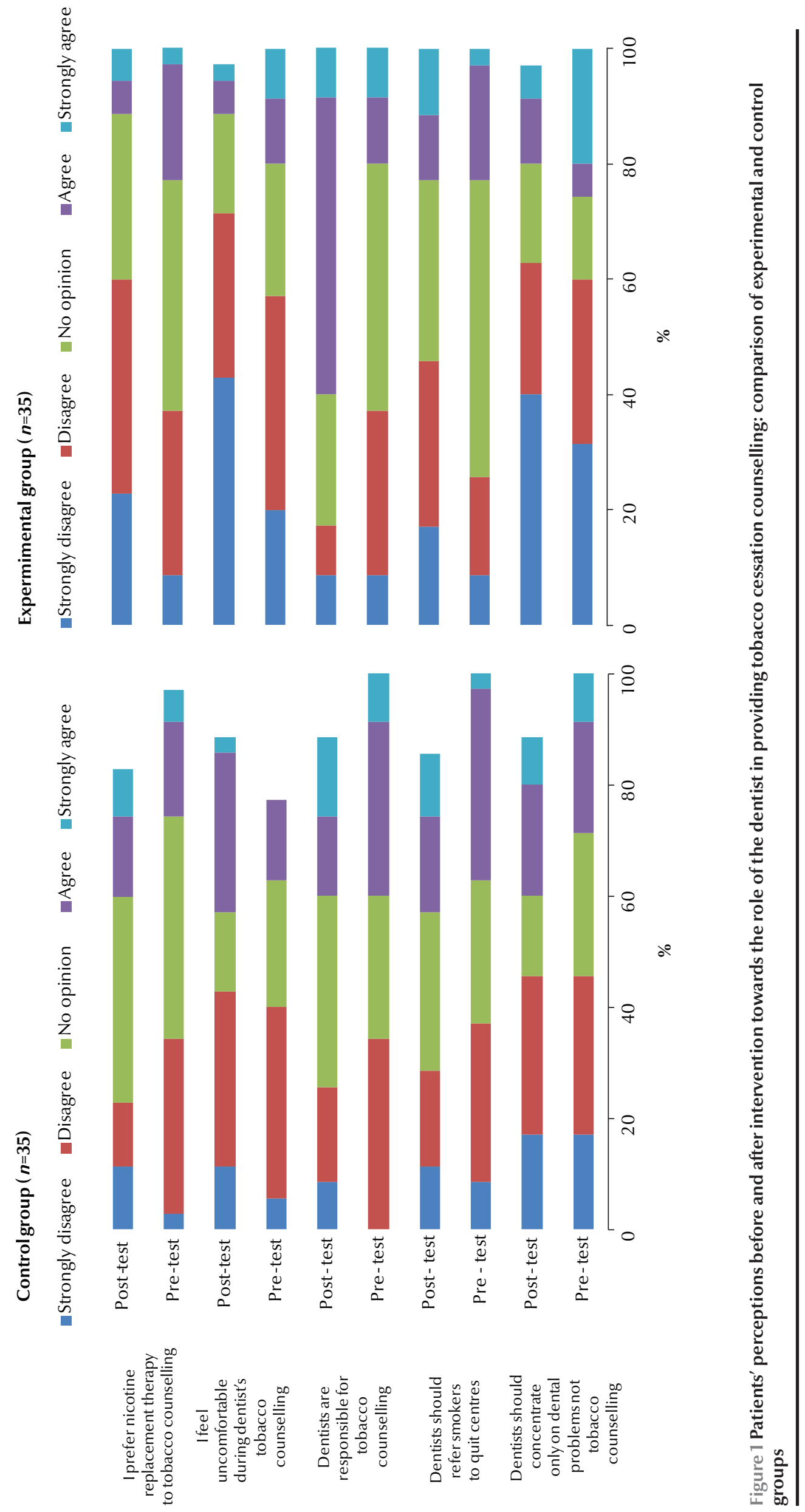




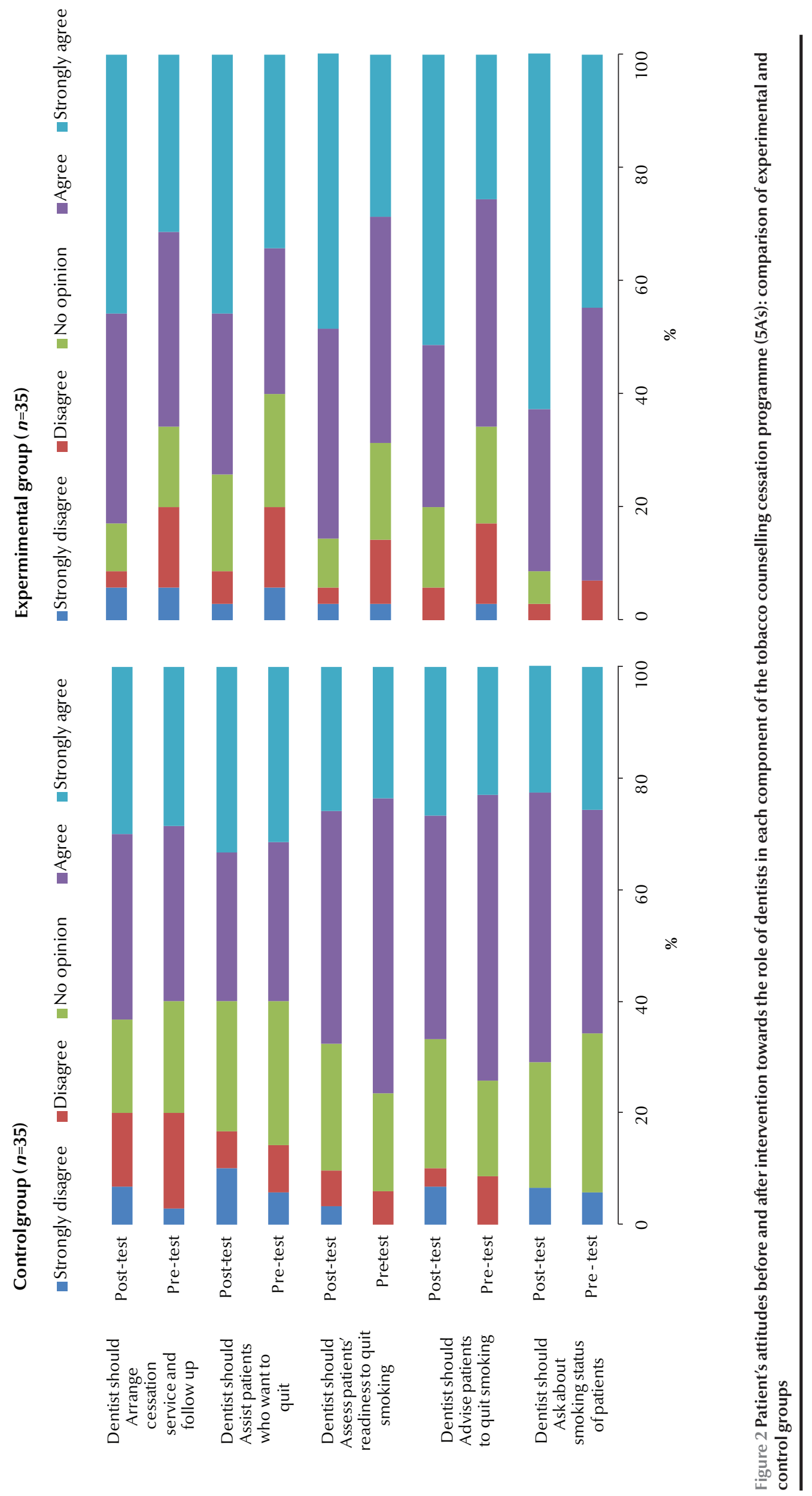




\begin{tabular}{|c|c|c|c|c|c|}
\hline \multirow[t]{3}{*}{ Stage } & \multicolumn{4}{|c|}{ Patient's attitude towards role of dentist in quitting smoking } & \multirow[b]{3}{*}{$P$-value ${ }^{\text {a }}$} \\
\hline & \multicolumn{2}{|c|}{ Control group $(n=35)$} & \multicolumn{2}{|c|}{ Experimental group $(n=35)$} & \\
\hline & Mean (SD) score & (Min.-max. scores) & Mean (SD) score & (Min.-max. scores) & \\
\hline Pre-test & $67.6(11.0)$ & $(49.98-90.0)$ & $69.1(16.8)$ & $(36.7-91.6)$ & 0.403 \\
\hline Post-test & $68.0(13.5)$ & $(38.31-88.3)$ & $77.4(15.4)$ & $(38.3-96.6)$ & 0.009 \\
\hline
\end{tabular}

aIndependent samples t-test.

$S D=$ standard deviation .

\section{Discussion}

This study was done to analyse the effect of brief counselling by a dentist on patients' attitude towards the dentist's role in tobacco cessation counselling in Tehran, Islamic Republic of Iran. Those smokers who had received the counselling demonstrated higher rates of positive attitudes after the intervention, which indicated a positive effect of counselling patients in this manner. Tobacco has major adverse effects on oral health and, in countries where people regularly visit their dentist, the oral health professional can have an important role in tobacco cessation programmes. Other studies in the dental setting have also reported successful tobacco counselling cessation programmes by dentists [2]. Although studies have shown that patients are receptive to physicians' counselling them about smoking - for example, Kivz et al. found that $90 \%$ of patients believed that it is the physician's responsibility to provide them with tobacco counselling cessation services [10] — there has been little research about attitudes towards dentists' counselling on tobacco cessation. Therefore, there is a limited ability to compare the current results with other findings.

Campbell et al. reviewed patients' perceptions of tobacco cessation services in dental offices in Canada. They found that $58.5 \%$ of patients believed that tobacco counselling cessation services should be offered in dental settings, although dentists did not agree and the majority of them viewed patient resistance and dentists' self-confidence as the main barriers to conducting tobacco counselling cessation services in the dental setting [11]. Our study demonstrated that, to some degree, patients' resistance and negative attitudes towards dentists' focus on quitting could be changed by a brief and simple counselling method. It is likely that the dentist-patient relationship could affect smokers' perceptions about counselling on smoking cessation. Certainly in studies of the general quality of dental care the patient-dentist relationship was a key factor influencing patients' judgement about the quality of care $[12,13]$.

There are likely to be a number of barriers that have to be eliminated in order to achieve positive attitudes to tobacco counselling. One barrier is the patient's perception of the dentist's role. Patients may see the dentist as the person whose job is to provide treatment for their teeth and not to provide smoking cessation counselling. In a study on barriers for Iranian dentists towards following guidelines for providing tobacco cessation programmes, patients' resistance was one of the most important barriers [9]. In the current study smokers were significantly more willing after the intervention to agree that dentists are responsible for tobacco counselling and to disagree that dentists should concentrate only on dental problems not tobacco counselling. After the counselling, patients generally accepted the dentist's role in providing support for smoking cessation. On the other hand, in a different study on the barriers to the dentist's role in encouraging quitting, patients preferred the dentist just to provide treatment for their teeth and not to provide smoking cessation counselling [11].

A limitation of this study is that we used the self-reported perceptions of patients, which may be subject to social desirability bias. Another limitation was that the study was based only on patients attending a public university clinic in one city; no sample was included from private dental offices, dentistry schools or different socioeconomic groups of society, which may increase the likelihood of patients reporting positive attitudes toward dental cessation counselling. Further research is needed to show the effectiveness of the counselling programme in promoting patients' behavioural change and quit efforts. Nevertheless, our study showed that after receiving a brief and simple counselling intervention Iranian patients had more positive attitudes toward receiving tobacco cessation advice from their dentist in dental offices. We recommend that more responsibilities should be transferred to dentists in tobacco prevention policies, including some modifications in the dental education curriculum.

Competing interests: None declared. 


\section{References}

1. Watt RG, Johnson NW, Warnakulasuriya KA. Action on smoking: opportunities for the dental team. British Dental Journal, 2000, 189:357-360.

2. Carr AB, Ebbert JO. Interventions for tobacco cessation in the dental setting. A systematic review. Community Dental Health, 2007, 24:70-74.

3. WHO report on the global tobacco epidemic, 2008. The MPOWER package. Geneva, World Health Organization, 2008.

4. Fiore MC. US public health service clinical practice guideline: treating tobacco use and dependence. Respiratory Care, 2000, 45(10):1200-1262.

5. Rockville MD. Treating tobacco use and dependence. Washington (DC), US Department of Health and Human Services, 2008.

6. Ebn Ahmady A et al. Dentists' familiarity with tobacco cessation program in dental setting in Iran. Journal of Public Health Dentistry, 2001, 71:271-277.

7. Meysamie A et al. Pattern of tobacco use among the Iranian adult population: results of the national Survey of Risk Factors of Non-Communicable Diseases (SuRFNCD-2007). Tobacco Control, 2010, 19:125-128.
8. Pakshir HR. Oral health in Iran. International Dental Journal, 2004, 54 (Suppl. 1):367-372.

9. Ebn Ahmady A et al. Dentists' familiarity with tobacco cessation programs in dental settings in Iran. Journal of Public Health Dentistry, 2011, 71:271-277.

10. Kviz FJ et al. Patients' perceptions of their physician's role in smoking cessation by age and readiness to stop smoking. Preventive Medicine, 1997, 26:340-349.

11. Campbell HS, Sletten M, Petty T. Patient perceptions of tobacco cessation services in dental offices. Journal of the American Dental Association, 1999, 130:219-226.

12. Goedhart H, Eijkman MA, ter Horst G. Quality of dental care: the view of regular attenders. Community Dentistry and Oral Epidemiology, 1996, 24:28-31.

13. Lahti $\mathrm{S}$ et al. Patients' expectations of an ideal dentist and their views concerning the dentist they visited: do the views conform to the expectations and what determines how well they conform? Community Dentistry and Oral Epidemiology, 1996, 24:240-244. 